Жилин С. Г., Комаров О. Н., Соснин А. А., Потянихин Д. А. S. G. Zhilin, O. N. Komarov, A. A. Sosnin, D. A. Potianikhin

ОСОБЕННОСТИ ФОРМИРОВАНИЯ ПОРИСТОЙ СТРУКТУРЫ ПРЕССОВОК ИЗ ПОЛИМЕРНОГО ДИСПЕРСНОГО МАТЕРИАЛА

\title{
SPECIAL FEATURES OF THE FORMATION OF POROUS STRUCTURE IN COMPACTS MADE OF DISPERSED POLYMERIC MATERIAL
}

Жилин Сергей Геннадьевич - кандидат технических наук, доцент, заведующий лабораторией Института машиноведения и металлургии ДВО РАН (Россия, Комсомольск-на-Амуре). E-mail: zhilin@imim.ru.

Mr. Sergey G. Zhilin - PhD in Engineering, Associate Professor, Head of laboratory, Institute of Machinery and Metallurgy, Far-Eastern Branch of Russian Academy of Sciences (Russia, Komsomolsk-on-Amur). E-mail: zhilin@imim.ru.

Комаров Олег Николаевич - кандидат технических наук, доцент, ведущий научный сотрудник Института машиноведения и металлургии ДВО РАН (Россия, Комсомольск-на-Амуре). E-mail: olegnikolaevitsch@rambler.ru.

Mr. Oleg N. Komarov - PhD in Engineering, Leading Researcher, Institute of Machinery and Metallurgy, FarEastern Branch of Russian Academy of Sciences (Russia, Komsomolsk-on-Amur). E-mail: olegnikolaevitsch@rambler.ru.

Соснин Александр Александрович - кандидат технических наук, научный сотрудник Института машиноведения и металлургии ДВО РАН (Россия, Комсомольск-на-Амуре). E-mail: sosnin@imim.ru.

Mr. Aleksander A. Sosnin - PhD in Engineering, Researcher, Institute of Machinery and Metallurgy the FarEastern Branch of Russian Academy of Sciences (Russia, Komsomolsk-on-Amur). E-mail: sosnin@imim.ru.

Потянихин Дмитрий Андреевич - кандидат физико-математических наук, старший научный сотрудник Института машиноведения и металлургии ДВО РАН (Россия, Комсомольск-на-Амуре). E-mail: potyanikhin@mail.ru.

Mr. Dmitrii A. Potianikhin - PhD in Physics and Mathematics, Senior Researcher, Institute of Machinery and Metallurgy, Far-Eastern Branch of Russian Academy of Sciences (Russia, Komsomolsk-on-Amur). E-mail: potyanikhin@mail.ru.

Аннотация. Получение выплавляемых моделей, применяемых в точном литье, формовкой порошков на основе воскообразных материалов позволяет повысить размерно-геометрические характеристики отливок преимущественно за счет устранения усадочных дефектов. Однако при формировании массивных элементов прессовок материал модели после снятия нагрузки упруго релаксирует. Кроме того, в ряде случаев наблюдается неравномерное распределение плотности в различных участках таких прессовок. Необходимость поиска оптимальных режимов формирования прессовки с минимальной анизотропией и, следовательно, минимальным значением упругого отклика уплотненного тела после снятия нагрузки определяет актуальность отраженных в работе исследований. В работе представлены результаты экспериментального определения варианта уплотнения порошкового тела, состоящего из однокомпонентного полимерного материала, с учетом его упругого отклика после снятия нагрузки. По результатам проведенных экспериментов построены зависимости температуры материала, находящегося в зоне контакта мундштука с прессформой от давления прессования. На основе экспериментальных данных установлено влияние теплофизических параметров процесса уплотнения порошкового тела на формирование усадки и упругого отклика материала прессовки.

Summary. Production of investment patterns for precision casting by molding of powders based on waxy materials makes it possible to improve dimensional and geometric properties of castings mainly at the expense of shrinkage defect elimination. However, during the formation of compact massive elements the pattern material relaxes elastically after load removal. In addition, non-uniform density distribution in different parts of the compacts is observed in a number of cases. The necessity of finding the optimal regimes of compact formation with minimal anisotropy, and therefore minimal value of elastic aftereffect of compacted porous body after load removal 
determines the relevance of this study. In this paper we introduce experimental determination of one variant of powder body compaction and subsequent elastic aftereffect due to load removal. Investigated powder body consists of single-component polymeric material. In accordance with the results of the experiments the dependence of material temperature in contact area between the die and the mold on compacting pressure was obtained. It was experimentally determined the influence of thermophysical properties of powder body compaction process on shrinkage formation and elastic aftereffect of compact material.

Ключевые слова: полимерный порошок, распределение плотности, пористость, прессовка, напряжение, температура, упругий отклик, анизотропия.

Key words: polymeric powder, density distribution, porosity, compact, stress, temperature, elastic aftereffect, anisotropy.

\section{УДК 621.74 .045}

Наиболее распространенным способом получения отливок сложной пространственной конфигурации с высокой размерно-геометрической точностью является литье по выплавляемым моделям [1]. Формирование литой заготовки при использовании такого способа происходит в керамической оболочковой форме, получаемой послойным нанесением огнеупорной суспензии на модельный блок с прикрепленными моделями отливок. Поверхность и свойства выплавляемых моделей во многом определяют качество получаемых по ним отливок. Выплавляемые модели получают заливкой жидкого (или запрессовкой пастообразного) модельного материала в прессформу. При таком способе формирования моделей возможно появление ряда дефектов, являющихся следствием связанных, как правило, усадочных процессов, проходящих при охлаждении модельной массы в пресс-форме. Учет этого явления представляется важным при проектировании пресс-форм. Перспективным представляется получение пористых выплавляемых моделей, лишенных недостатков, указанных выше.

К преимуществам альтернативного способа получения точного литья по пористым прессованным выплавляемым моделям можно отнести устранение усадочных явлений, поверхностных неровностей моделей, повышение стойкости керамических оболочковых форм к образованию трещин в процессе выплавления моделей из них [2]. Пористые выплавляемые модели получают формованием порошков модельных композиций различных фракций. Модельные композиции 1 группы представляют собой, как правило, двухкомпонентный сплав парафина и стеарина в различных пропорциях [1]. Прессованные пористые модели отличаются от традиционных выплавляемых моделей физико-механическими свойствами, размерно-геометрической точностью $[3,4]$. Плотность пористых моделей на 8-12 \% ниже, чем традиционных выплавляемых, полученных запрессовкой жидкого или пастообразного модельного состава в пресс-форму. Так, прочность на изгиб однокомпонентных прессованных моделей с указанной выше плотностью (состоящих из парафина) $\approx 1,0 \ldots 1,1$ МПа. Такая прочность представляется допустимой, обеспечивающей конструкционную целостность модельного блока в ходе технологических операций. Модельный блок представляет собой единую конструкцию, состоящую из элементов литниково-питающей системы и выплавляемых моделей отливок. Отливки, получаемые литьем по выплавляемым моделям, должны соответствовать 11-16 квалитетам при допусках на размеры рабочей полости прессформы, не превышающих 8-9 квалитетов (ГОСТ 25347-82) [2]. Экспериментально установлено, что размерно-геометрическая точность пористых прессованных моделей простой конфигурации соответствует 9-10-му квалитету, что выше, чем у традиционных выплавляемых моделей.

Однако при получении прессованной модели сложной пространственной конфигурации наблюдается неравномерное распределение плотности в различных ее участках. Так, значение плотности массивных элементов ниже, чем плотность участков с меньшей площадью поперечного сечения. Величина упругого отклика прессовок снижается с увеличением пористости. По завершении релаксации материала такие характеристики конечной прессовки, как плотность, прочность и др., несколько отличаются от расчетных значений. 
При прессовании модельного порошка за счет его трения о стенки пресс-формы предположительно происходит оплавление периферийных зон будущей модели и воздух, расположенный в центральных ее участках, не имеет свободного выхода. Параметрами, определяющими величину упругого отклика прессовки при «холодном» уплотнении полимерного дисперсного материала, являются скорость уплотнения, удельное давление, температура материала до уплотнения и после извлечения прессовки из формы. В данном случае для получения прессовки после уплотнения не требуется ее нагрев, т.к. процесс осуществляется за счет появления локальных зон разогрева контактов частиц, из которых состоит порошковое тело. В технологиях холодного прессования, применяемых в порошковой металлургии, принято, что величина частиц порошка лишь частично оказывает влияние на значение давления прессования [5]. Однако ввиду высокой пластичности используемого при получении прессованной пористой модели полимерного порошка его фракция оказывает влияние на величину давления прессования и на упругий отклик сформированного порошкового тела после его разгрузки.

По завершении процесса формирования прессовки воздух, заключенный в пресс-форме с воскообразным модельным материалом, после снятия нагрузки и разъема формы упруго релаксирует. На рис. 1 представлен элемент демонстрационной пресс-формы с прозрачными внешними стенками, в которой воскообразный состав фракции 1,0 мм уплотняли односторонним прессованием. Видно, что после разгрузки прессовка расширяется.

a)

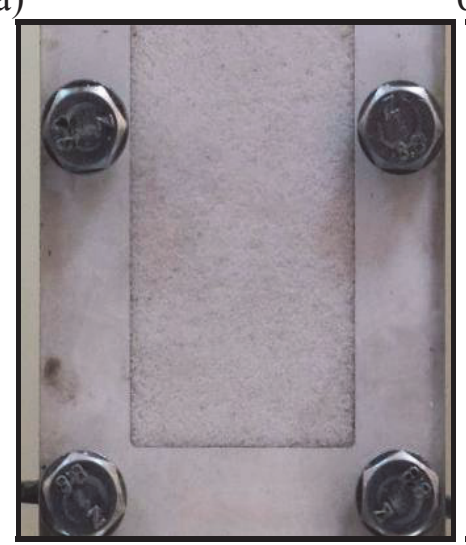

в)

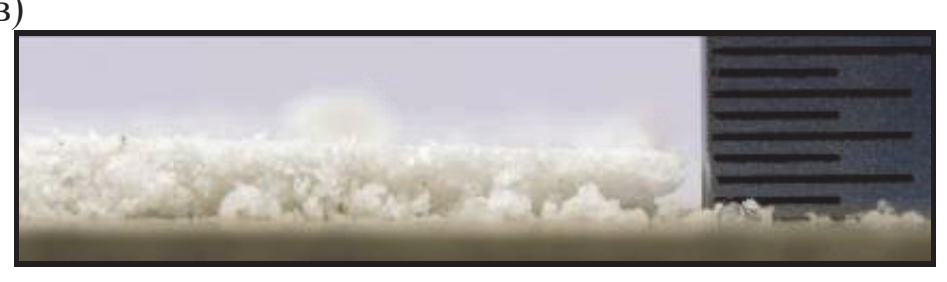

б)

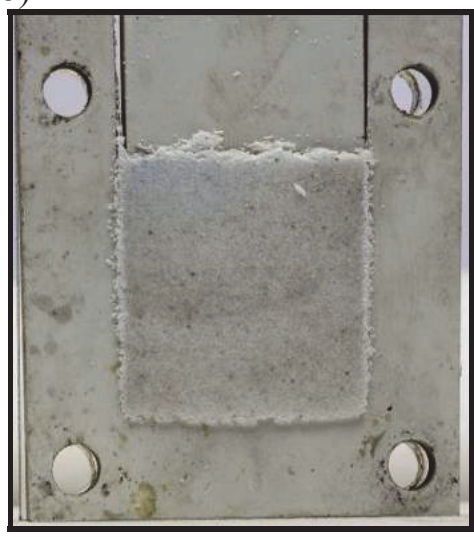

Рис. 1. Упругий отклик прессовки из воскообразного материала фракции 1,0 мм: a - уплотненного в демонстрационной пресс-форме до плотности 880 г $\mathrm{cm}^{3}$;

б - пресс-форма разгружена; в - упругий отклик материала прессовки в направлении поперечном прессованию

На величину упругого отклика порошкового тела также влияет фракция материала. На рис. 2 представлены зависимости упругого отклика для порошкового тела, получаемого из воскообразного материала различных фракций.

Из рис. 2 видно, что размеры прессовок после снятия нагрузки увеличиваются в продольном прессованию направлении на $0,7-1,2 \%$, а в поперечном - на 0,4-0,5 \%. Сокращение упругого отклика прессовок возможно введением в исходные композиции порошковых тел растворимых компонентов фракций, соответствующих воскообразному материалу [6]. 


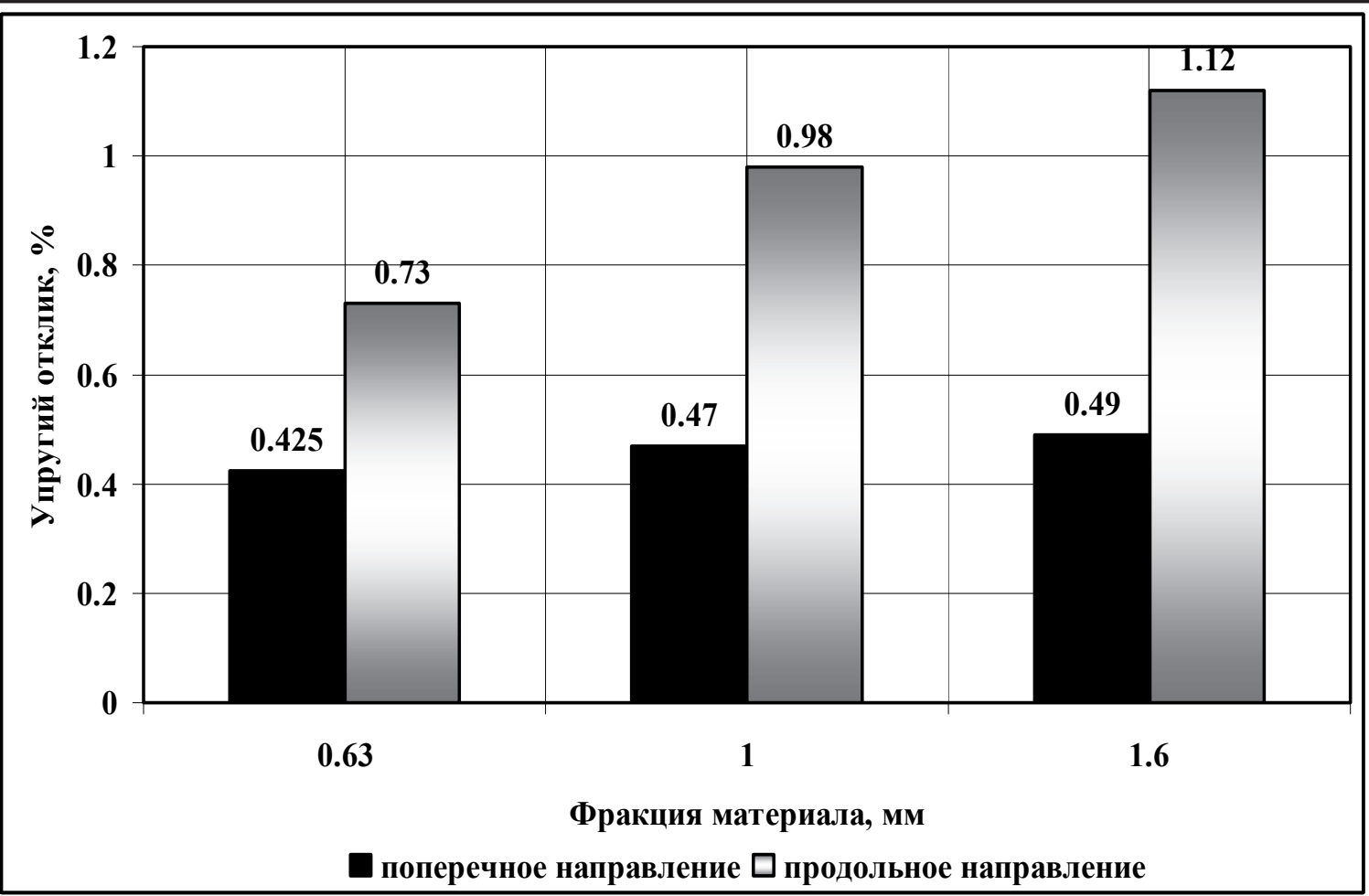

Рис. 2. Зависимость упругого отклика воскообразного модельного материала от фракции: $1-0,63$ мм; $2-1,0$ мм; $3-1,6$ мм

Кроме того, при одноосном прессовании наблюдается неравномерное распределение плотности материала в выплавляемой модели. Так, например, поверхностная твердость и плотность выплавляемой модели в зонах, соприкасающихся с пресс-пуансоном, выше, чем в противоположных участках.

Таким образом, поиск варианта формирования равномерного распределения плотности и, следовательно, физико-механических характеристик и упругого отклика порошкового тела после снятия нагрузки представляется актуальной задачей в настоящем исследовании.

Целью работы является определение оптимального варианта формообразования пористой прессованной модели из полимерных дисперсных композиций, при котором достигается снижение влияния упругого последействия прессовок на их размерно-геометрическую точность с сохранением требуемых прочностных характеристик.

В рамках поставленной цели решались следующие задачи:

- определения изменения температуры, возникающего в области сопряжения основного цилиндра и мундштука при уплотнении материала;

- определения упругого отклика длинномерного формованного изделия при различных режимах его формирования из порошкового полимерного материала.

Сложность прогнозирования конечных размеров прессовки в виду наличия упругого отклика материала после снятия нагрузки определяется неравномерностью распределения свойств в ее объеме. Модельный материал в диспергированном виде в процессе прессования проявляет свойства пластичности и текучести. Дисперсную сыпучую среду можно сравнить с жидкостью лишь отчасти. В среде, состоящей из полимерных элементов, определить такие характеристики текучей среды, как скорость движения, давления и плотности, численными методами не представляется возможным. Текучесть однородной смеси, по Г.М. Орлову [7], - это способность элементов предварительно уплотненной смеси к взаимным перемещениям без разрыва связей под действием сил, превышающих сопротивление сдвигу. Таким образом, если порошковый материал не уплотнен до заданной плотности, то отсутствует его текучесть. Так как в объеме подвергающейся прессованию 
системы плотность распределяется неоднородно - локальное воздействие указанных выше свойств растет с увеличением деформации системы.

В классической теории механики грунтов [8] пластичность - напряженное состояние, при котором материал способен изменять форму без изменения объема и нарушения сплошности, т.е. сопротивление сдвигу материала изучается в условиях предельного напряженного состояния, соответствующего незатухающим скольжениям (сдвигам) одной части слоя материала над другой. Действующие на материал критические нагрузки при таком состоянии вызывают последовательные сдвиги, приводящие к необратимым деформациям. Экспериментально установлено, что при прессовании порошков воскообразных модельных материалов отдельные их частицы начинают деформироваться при малых давлениях прессования, но и при более значительных давлениях наблюдается горизонтальное перемещение частиц, характерное для первой стадии уплотнения. Поэтому чем пластичнее материал, тем при более низких давлениях начинается уплотнение, связанное с деформацией частиц. Высокая пластичность [9] воскообразного модельного материала определяет формирование изделия при относительно невысоком давлении, поэтому в ряде случаев полученные прессовки легко деформируются даже под действием собственной массы. Переуплотнение, как во всем объеме прессовки, так и в локальных ее участках, определяет наличие упругого последействия материала пористой воскообразной выплавляемой модели в процессе формирования последней [10].

Прочностные характеристики пористых выплавляемых моделей из воскообразных материалов при плотности на 10 \% меньшей, чем плотность этого материала в литом состоянии удовлетворяют технологическим требованиям и не оказывают расширяющего воздействия на керамическую форму при выплавлении из нее [6]. Экспериментально установлено, что при формировании прессовки из дисперсного полимерного материала наибольшая плотность достигается в зонах контакта материала с формообразующей поверхностью пресс-формы, а при получении сложной прессовки требуемая плотность во всех ее участках не достигается. Скорость уплотнения полимерных модельных материалов безусловно влияет на появление упругого отклика таких прессовок [2].

Для оптимизации технологических и эксплуатационных свойств выплавляемых моделей в специальных видах литья преимущественно используют многокомпонентные модельные материалы. Однако в ходе эксперимента предпочтительно использовать однокомпонентный материал. В качестве материала для порошкового тела использовали полимерный однокомпонентный материал на основе парафина (Парафины нефтяные твердые. Технические условия. ГОСТ 23683-89) фракций 0,63-1,6 мм. Так как нефтяной парафин является относительно легкоплавким материалом, то среди предлагаемых ГОСТ 23683-89 выбираем парафин марки Т1. К свойствам, определяющим параметры процесса уплотнения этого материала, отнесем: плотность материала, полученного свободной заливкой 930 г/см³ с учетом распределенной пористости; температуру плавления, определенную при помощи прибора дифференциально-термического анализа Shimadzu DTG-60H $60{ }^{\circ} \mathrm{C}$ (ГОСТ 23683-89 регламентирует температуру плавления для парафина марки Т1 52-58 ${ }^{\circ} \mathrm{C}$.); насыпная плотность фракций материала 0,63-1,6 мм составляет, соответственно, 310-330 г/ $\mathrm{cm}^{3}$.

Эксперимент заключался в определении температуры и упругого отклика материала прессовки при уплотнении порошка модельного материала, помещенного в стальной цилиндр, как показано на рис. 3. Верхняя часть цилиндра снабжена пресс-пуансоном, который перемещали с различной скоростью. В нижней части цилиндра располагался мундштук с диаметром отверстия меньшим диаметра пресс-пунасона в 5 раз. В зоне контакта мундштука с цилиндром установлена термопара хромель-копель (ТХК), предназначенная для проведения замеров температуры в диапазоне от - 20 до $200{ }^{\circ} \mathrm{C}$. Каждый эксперимент в серии выполнялся при постоянной скорости перемещения пресс-пуансона. Скорость перемещения пресс-пуансона в серии экспериментов изменялась в диапазоне от 0,25 до $5 \mathrm{mM} / \mathrm{c}$. По достижении определенной плотности в порошковом теле в результате перемещения пресс-пуансона воскообразный модельный материал поступал в мундштук и выходил из него в виде длинномерной прессовки круглого сечения. 
Рис. 3. Схема реализации процесса получения длинномерной прессовки путем уплотнения полимерного дисперсного материала в металлическом цилиндре: 1 - цилиндр; 2 - мундштук; 3 - пресс-пуансон

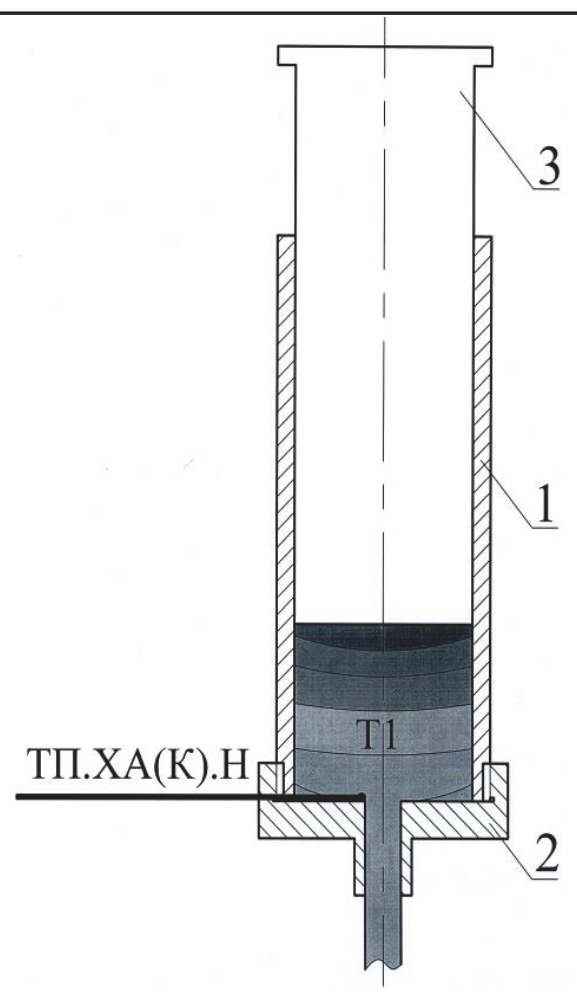

В ходе эксперимента осуществлялись регистрация температуры в зоне контакта мундштука с формой, а также упругий отклик получаемой длинномерной прессовки на всем ее протяжении с интервалом замера 0,05 м. Величину упругого отклика определяли по формуле

$$
\mathrm{O}_{\text {упр }}=\left(\mathrm{A}_{1}-\mathrm{A}_{0}\right) \cdot 100 \% \text {, }
$$

где $\mathrm{O}_{\text {упр }}$ - величина упругого отклика, \%; $\mathrm{A}_{1}$ и $\mathrm{A}_{0}$ - соответственно контролируемые размеры внутреннего диаметра мундштука и внешнего диаметра длинномерной прессовки, мм.

По результатам проведенных экспериментов построены зависимости температур $\left({ }^{\circ} \mathrm{C}\right)$ в зоне контакта мундштука с пресс-формой в уплотняемом материале от напряжений (МПа), возникающих при сопротивлении материала уплотнению. Экспериментально установлено, что скорость перемещения пресс-пуансона при уплотнении оказывает существенное влияние на теплофизические условия формирования длинномерной прессовки и упругий отклик уплотненного материала. На рис. 4 представлен график, характерный для уплотнения материала при скорости перемещения пресс-пуансона $1,25 \mathrm{~mm} / \mathrm{c}$.

На рис. 4 обозначены позиции: I - зависимость температуры $\left({ }^{\circ} \mathrm{C}\right)$ в зоне контакта мундштука с пресс-формой в уплотняемом материале от возникающих при сопротивлении материала уплотнению, напряжений (МПа); II - температура, при которой уплотняемый материал поступает в мундштук; III - элемент длинномерной прессовки на выходе из мундштука. Из рис. 4 видно, что температура растет пропорционально увеличению напряжения в уплотняемом материале, a еe максимум приходится на максимальное значение напряжений. Зарегистрированная в рассматриваемом эксперименте температура, при которой материал начинает поступать в формообразующий элемент цилиндра, составила $23,7^{\circ} \mathrm{C}$, в то время как температура плавления парафина материала на 50-60 \% выше. На температурные данные в представленной схеме уплотнения существенное влияние оказывает материал конструкции, из которого выполнен цилиндр. 


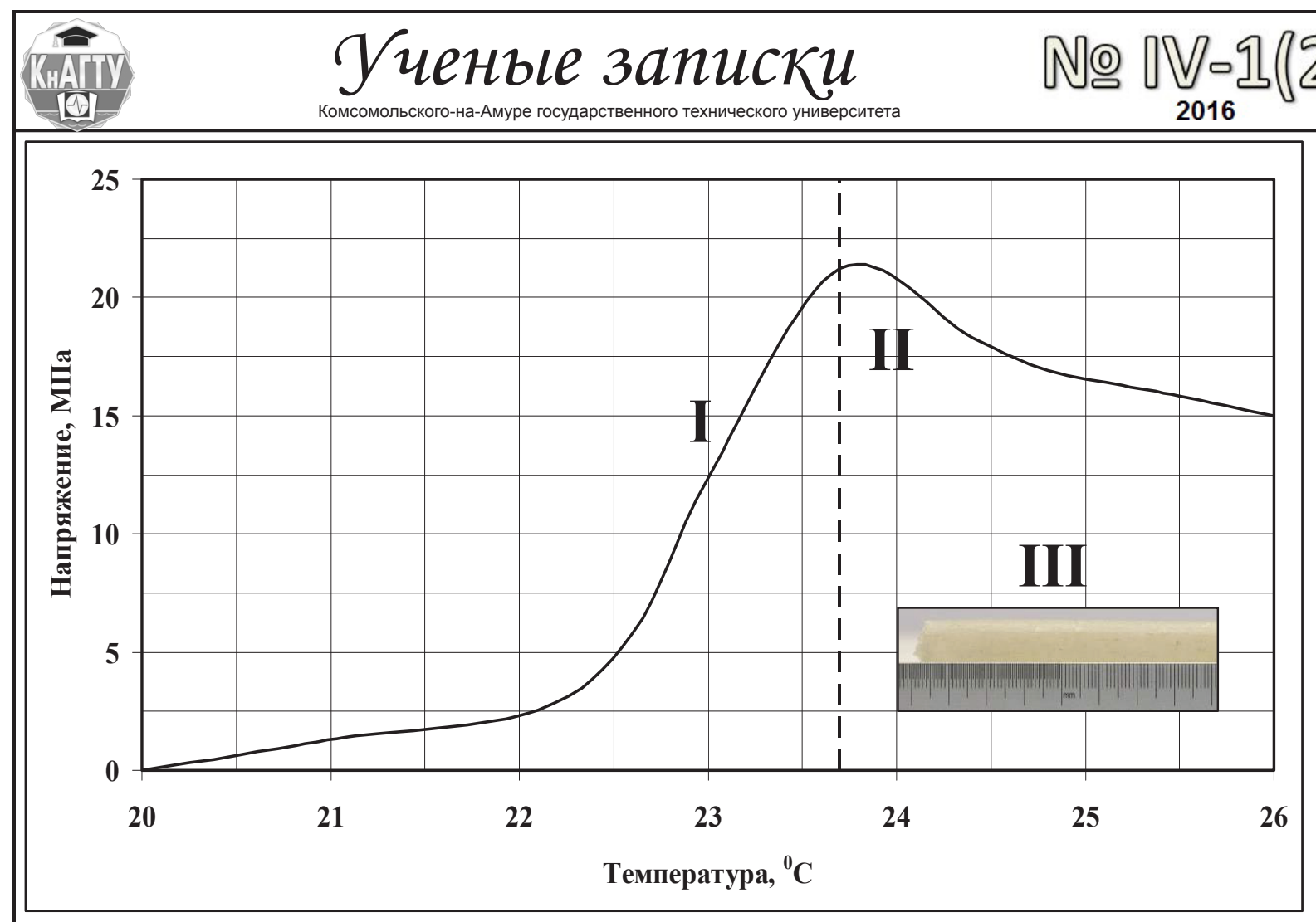

Рис. 4. Зависимость температуры $\left({ }^{\circ} \mathrm{C}\right)$ в зоне контакта мундштука с пресс-формой в уплотняемом материале от напряжений (МПа), возникающих при сопротивлении материала уплотнению

Экспериментально установлено, что с увеличением скорости перемещения пресс-пуансона возрастает напряжение: при увеличении скорости с 0,25 до 5 мм/с напряжение возрастает на $30 \%$. Наименьший упругий отклик (на 12-18 \% меньше, чем показано на рис. 2) уплотняемого материала после снятия нагрузки достигается в интервале скоростей перемещения пресс-пуансона 0,25-1,5 мм/с. С увеличением скорости уплотнения в прессовке после снятия нагрузки появляются отрицательные значения величины упругого отклика, характеризующие появление усадочных дефектов, связанных с перегревом материала.

Экспериментально определены варианты формообразования прессовок с учетом упругого отклика, возникающего при различных условиях уплотнения: скорости уплотнения, времени выдержки уплотненного материала в пресс-форме после завершении уплотнения. Таким образом, управление величиной упругого отклика материала уплотняемого порошкового тела возможно путем регулирования нагрузки при прессовании. Теплофизические условия формирования прессовки из порошкового тела без внешнего подведения тепла определяются величиной нагрузки, создаваемой при передаче давления прессования порошковому телу. В ходе эксперимента установлены предпочтительные режимы прессования полимерного дисперсного материала, при которых достигается равномерная плотность в объеме прессовок, позволяющая сократить упругий отклик последних на $12-18 \%$.

Работа выполнена при частичной финансовой поддержке гранта ДВО РАН (проект 15-I-4018) «Расчетное и опытное совершенствование процессов профилирования и высокоточного литья на основе новых модельных представлений и специальной серии вычислительных экспериментов. (Раздел 4)».

\section{ЛИТЕРАТУРА}

1. Литье по выплавляемым моделям / под общ. ред. В. А. Озерова. - 4-е изд., перераб. и доп. - М.: Машиностроение, 1994. - 448 с.

2. Жилин, С. Г. Упругий отклик прессовок при деформировании гетерогенных порошковых материалов / С. Г. Жилин, О. Н. Комаров, И. Г. Сапченко // Вестник ЧГПУ им. И.Я. Яковлева. Серия: Механика предельного состояния. - 2015. - № 4(26) - С. 184-191. 
3. Жилин, С. Г. Влияние упругого отклика деформируемого порошкового полимерного материала на размерно-геометрические параметры прессовки / С. Г. Жилин, И. Г. Сапченко // XI Всероссийский съезд по фундаментальным проблемам теоретической и прикладной механики: сборник докладов (Казань, 20-24 августа 2015 г.). - Казань: Изд-во Казан. ун-та, 2015. - С. 1383-1385.

4. Жилин, С. Г. Технологические особенности обратимых деформаций при разгружении прессованных дисперсных полимерных композиций / С. Г. Жилин, И. Г. Сапченко // Материалы VIII Всероссийской конференции по механике деформируемого твердого тела (Чебоксары, 16-21 июня 2014 г.): в 2 ч. Ч. 1 / под ред. Н. Ф. Морозова, Б. Г. Миронова, А. В. Манжирова. - Чебоксары: Чуваш. гос. пед. ун-т, 2014. - С.156-158. 5. Ермаков, С. С. Порошковые стали и изделия / С. С. Ермаков, Н. Ф. Вязников. - 4-е изд., перераб. и доп. Л.: Машиностроение. Ленингр. отд-ние, 1990. - 319 с., ил.

6. Сапченко, И. Г. Об особенностях проектирования и использования оснастки при изготовлении пористых выплавляемых моделей / И. Г. Сапченко, С. Г. Жилин, А. И. Евстигнеев // Литейное производство. - 2010. № 2. - C. 26-31.

7. Орлов, Г. М. Текучесть формовочных смесей / Г. М. Орлов // Теория формовки: Тр. VI совещ. по теории литейных процессов. - М.: Изд-во АН СССР, 1961.

8. Цытович, Н. А. Механика грунтов (краткий курс): учебник для строит. вузов / Н. А. Цытович. - 4-е изд., перераб. и доп. - М.: Высш. шк., 1983. - 288 с., ил.

9. Медведев, Я. И. Технологические испытания формовочных материалов / Я. И. Медведев, И. В. Валисовский - М.: Машиностроение, 1973. - 312 с.

10. Особенности формирования и разрушения прессовок из полимерного порошкового материала И. Г. Сапченко, С. Г. Жилин, О. Н. Комаров, А. А. Соснин // Успехи механики сплошных сред: сб. докл. Международной конференции, приуроченной к 75-летию академика В.А. Левина. - Иркутск: Мегапринт, 2014. - C. 428-432. 